used exceeding that of either anthracite coal or coke, but in that year the consumption of anthracite exceede that of charcoal; in 1869 the consumption of coke ex-
ceeded that of charcoal; in 1875 the consumption ex ceeded that of charcoal; in 1875 the consumption ex-
ceeded that of either charcoal or anthracite coal; in 1880 the consumption of coke exceeded that of both charcoal and anthracite combined, and this supremacy of coke has been maintained and extended ever since. The account for the consumption of coke in the
United States in the census year may be thus set forth:

Coke produced
Coke imported

Total

(5)

219,529

Coke used in iron and steel industry $\overline{\overline{20,378,452}}$

Coke exported

Coke used for all other purposes.

Total

$4,368,092$

USES OF BY-PronUCTS.

$25,362,817$

The ammoniacal liquor coming from the washers contains from 0.5 to 2 per cent of ammonia existing in a variety of compounds. It is so weak it must be further treated before it is marketable. On subjecting it to heat, part of this ammonia, known as free ammonia, comes off and may be collected in water. The rest may be liberated by heating the liquor with lime or
some other alkali. The treatment then consists in distilling the liquor with lime and either collecting the distillate in sulphuric acid so as to form ammonium sulphate, or else condensing it with sufficient steam to form a strong liquor containing from 15 to 20 per cent of ammonia. The ammoniacal liquor from by-product coke ovens, gas works, boneblack factories, and blast furnaces is the chief source of the ammonia water anhydrous ammonia used in refrigeration, and the ammonium compounds of commerce. Ammonium sulphate is used in the manufacture of alum and other compounds and as an ingredient of fertilizers. The quantity of ammonium sulphate reported as used in the present census year in fertilizers was $21,080,000$ pounds. The total product of ammonium sulphate reported for that year was $31,546,763$ pounds, and the ported for that year was $31,546,763$ pounds, and the
amount imported $30,576,558$ pounds, or a total of 62 , 123,321 pounds, so that but slightly over one-third of the available supply was consumed in the manufacture of fertilizers.

The tar which results from the dry distillation of coal is a mixture of a variety of hydrocarbons, amines, phenols, and other organic substances together with the coal treated and the manner in which it is treated. the coal treated and the manner in which it is treated, that it contains only about 14 per cent of free carbon, while gas-house tar contains as much as 28 per cent. This is due to the much higher temperature of the gas retort, the greater rapidity with which the maximum temperature is attained, and the smaller charge used. The percentage of tar acids is also greater in gas-house tar than in coke-oven tar. The tar acids from cokeoven tar contain a high percentage of cresol, thus neces phenn and pharmation is used in making tarred paper, paint, and varnishes is used in making tarred paper, paint, and varnishes for weight, to s; and as a the for weight, to crude petroleum in fuel value. Five pounds of tar are practically equal to from 7 to
pounds of coal. When heated to $250 \mathrm{deg}$. C., to drive off the volatiles, coal tar pitch is produced, which is used in making tar macadam pavements, about 2 galons being used per square yard of finished road. A cording to Pennock, "as a consumer of tar, the tar macalo for 1903 will absorb 4,000,000 gallons, or the product of the dry distilation of 400,000 tons of coal." The tar 44000 square vards; late and contracted for in 1903 , 2,01,000 square yards, so that this industry is a con, the tar to obtain the pitch brillo is divided into two portions - the pitch the distillate is divided into two portions- that which is lighter than water and that which is heavier. The The heavy oil is in demand for creosoting timber. Two grades of pitch are usually made-paving pitch and roofing pitch.

The volume of gas evolved from a by-product oven is determined directly by the quantity of volatiles in the coal used and the heat applied. The quantity with the coal. If the coal contains 32 to 34 per cent of volatile matter, from 50 to 55 per cent of the gas must be returned, but less gas suffices for those containing less volatile matter. The composition of the gas varies throughout the operation, it being richer in ginning. In separating the gas, in order to sell the surplus, the first running from 22 down to 14 candlepower are taken. This comes off on an average in the first ten hours of the operation. The rest of the known as the lean gas, is that which is used in heatin the coke ovens. Sometimes the benzol is remove from this lean gas and added to the surplus gas to benzol is removed by scrubbing the gas with tar oil, which dissolves it and then recovering the hydrocarbon from the tar oil by fractional distillation. Gas from by-product plants is sent considerable distances. The plant at Everett, Mass., supplies Boston and the sur pumped 11 miles to Baltimore; from the Camden, N. J., pumped 11 miles to Baltimore; from the Camden, N. J., plant it is pumped 38 miles to Trenton; and the $\mathrm{Du}-$
luth plant supplies the cities of Duluth and Superior.

\section{MULTIPLEX TELEPHONY.} By Chiarles S. Walden.

IT is but natural that those of an inventive turn of mind should have made attempts early in the development of the telephonic art by which a telephon
circuit might be used for several simultaneous con versations without interference.

Quite a number of the ideas developed have their fundamental principle contained in a patent for a "telegraph circuit" issued to Frank Jacob in England in 1882 and in this country in 1883 (No. 287,288). This is a plan by which two metallic circuits are com bined through proper resistances, arranged on the principle of a Wheatstone bridge, so that a third non interfering circuit is formed, using the earth for on

Apparently the first patent for a multiplex telephone Apparently the first patent for a multiplex telephone
circuit was issued to J. A. Barrett in 1886 . This was circuit was issued to J. A. Barrett in 1886. This was
a system similar to th\% principles contained in the a system similar to the principles contained in the
telegraph circuit above referred to; also the combination could be so arranged that a metallic circuit could be utilized in connection with the ground return and be utilized in connection with the ground return and
thus form a duplex. Subsequent patents followed, and to date about 28 patents for multiplex telephony and to date about 28 patents for multiplex telephony
have been issued. These cover every conceivable com have been issued. These cover every conceivable com-
bination and arrangement of circuits in order to produce the desired results, and as is the case in all duce the desired results, and as is the case in all
classes of subjects, there appears the "freak" type and others that while they may not come under the heading of "freaks" are far from being capable of practical application. Per contra some of the best engineering talent has contributed to the cause and brought out good designs.

In its simplest form the theoretical design of multiplex circuit would consist of two metallic circuit of equal length and of the same electrical dimensions, coils so as to form a third circuit; this arrangement is illu as to form a third circult, this arrangement is illustrated below. The coil connected across the arcult $A$ ina a single core coll with two windings $s$ retardation is maximum; whereas connected in paral lel $(C A$ and $C B)$ the magnetic effect is nil.

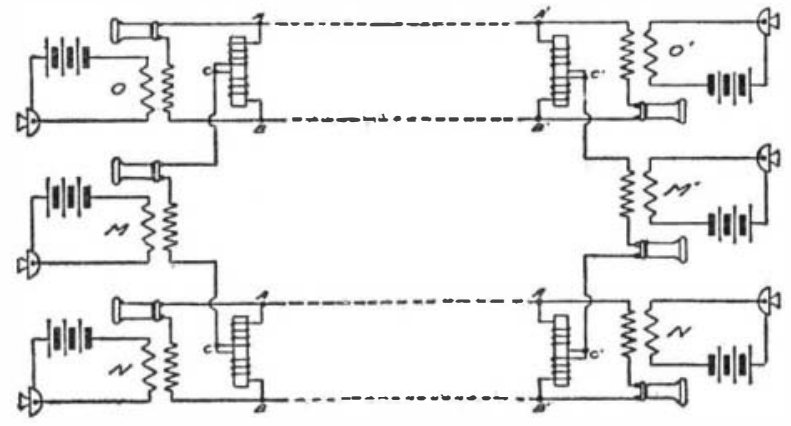

MULTIPLEX TELEPHONY.

It will be seen that current from the telephone $M$ or $M^{\prime}$ arriving at the point $C$ or $C^{\prime}$ divides and an
equal amount passes to $A$ and to $B$. The two line equal amount passes to $A$ and to $B$. The two line
wires $A$ and $B$ being of the same potential sign at any particular instant, there is no difference of potential and hence no flow of current from one wire to the
other through the telephone $O$ or $O^{\prime}$. Under these con other through the telephone $O$ or $O^{\prime}$. Under these con-
ditions three conversations may be carried an simulditions three

To obtain a retardation coil of the proper type it is necessary that the two windings upon one core be
wound simultaneously so that the wires are side by wound simultaneously so that the wires are side by
side, and that one winding equals the other, both as side, and that one winding equals the other, both as
to ohmic resistance and magnetic effect. As stated to ohmic resistance and magnetic effect. As stated
before, the line wires of both circuits should bear an equal relation to each other as to length, resistance, leakage and other electrical dimensions. It would furthermore necessitate their being run upon the same
poles and situated with respect to each other so as to poles and situated with respect
produce a balanced condition.

While these conditions ratory it is difficult for them to be even approximate under commercial conditions, and even if these conditions are established they are liable to be upset by
natural causes. From this it will be seen why duplex telephony has as yet not become a prominent factor.
to

THE BEHAVIOR OF THIN ALUMINIUM FOIL IN ELECTROSTATIC FIELDS.

Some highly interesting experiments on the be are recorded by $\mathrm{E}$. Bandl in a paper recently published in a German physical journal. $\uparrow$ These experiments are especially noteworthy because of the analgies they afford with cosmical phenomena.

If a small piece of aluminium foil be introduced be ween the terminal spheres of a working Wimshurst the polar field. In some cases even two or thre pieces of aluminium foil can thus be introduced into air, either independently of one another or clinging together.

*Electrical World.
In this caperiment care should be taken to eliminate any disturbing influence of the remaining parts of the apparatus on the conductors of the machine,
nor should there be any irregular loss in tension from either of the terminals. In the case of a constant rotation of the machine, the suspended foil will perform some slow motions, and sometimes a slight vibrating will be observed. Rows of sparks connecting
the metal foil with one or both terminals will be obthe metal foil with

If the operation of the machine be discontinued, the
serve in the dark. phenomenon will continue without any apparent change for a short time if condensers be inserted in the machine. However, the suspended foil gradually
becomes disturbed, commencing to oscillate between the two spheres with increasing speed and amplitude, as long as the condenser charge suffices. After this has been used up, the foil is frequently thrown out of
the field, while in other, less frequent cases, it will cling to the sphere

After the foil has been once thrown out of the field, it may be drawn again into the electric field by start-
ing the machine immediately afterward, there to be ing the machine immedian

Though the above phenomena cannot be perfectly explained, the following considerations might at least partly account for them:

Owing to the "point" effects, the aluminium foil spheres, thus being subject to the corresponding forces of attraction or repulsion of the terminals. The metal foil, because of the rapidity of alternation in the direction of charge, performs longitudinal vibrations, the amplitude of which is greatly damped by the relatively high mechanical air resistance. In the case of
a sufficiently high electric tension this alternation in direction may become so rapid that the resulting vibrations are not noticed by the eye, owing both to the extremely considerable damping effects and the high will ancy. As soon as this state is reached, the foil will a

The above is borne out by the following facts:

If a short piece of a very thin metal thread be in troduced between two metal spheres, connected with in linseed oil, this thread will show in the electric field a behavior similar to that of the aluminium foil; the vibrations, however, will not be very distinct (possibly because of the greater bulk of the metal wire) If the charge of the spheres exceeds a given limit, a spark discharge will take place in the oil with the intermediary of the suspended metal wire. Immediately before such discharges the above vibration is gensistance of the oil is readily recognized from the above.

Any monolateral disturbance in the electrostatic disturbances are due probably to the action of the disturbances are due probably to the action of the
field. Certain hitherto unknown electrostatic pressure effects, however, are likely to play some part in this connection.

If now the metal foil be deformed, e. g., by slightly rushing it between the fingers, the floating phenomena immediately become more complicated, additional components of motion being produced. The most characteristic feature of these phenomena is that the foil in most cases rotates around its axis. So far from being suspended midway between the two terminals, the foil now remains near one of them, more frequently close to the upper segment. The closer this "electric top" approaches the sphere, the more rapid will be the rotation generally. However, in the case of an especially intense working of the machine, the foil frequently rises to a considerable height, with These phenomena are attended by a strong electric wind emanating from the rotating foil.

wind emanating from the rotating foil.
Other highly interesting experiments were made with the "electric top." After removing the other terminal sphere as far as possible from the former (connecting it with earth if necessary) so as to con (a) performing the rotation round in fact, the electric top would migrate along a
tion; in considerable portion of the surface of the sphere (nostly at some distance from the latter) while tracing the most varied curves. In a dark room these
curves could be seen projected as luminous lines on the surface of the polar sphere in question. In fact, the whole of the foil would become luminous, and the most varied figures of rotation, due either to the rota-
tion round the axis or to the secondary motion of the tion round the axis or to the secondary motion of the of the foil was more complicated.

If the distance traversed by the rotating foil for some reason or other be increased considerably, the ing from the neighborhood of the poles to the vicinity of the equator of the terminal sphere. This motion can even be controlled to some extent by the aid of some conductor (even a finger). If the metal foil be then maintained for some time close to the equator of another great circle of the snhere at a moderate speed and at a considerable distance from the conductor In the case of such a revolution, the rotation around the axis is either discontinued or slackened.

The author draws attention to the undoubted analogy that exists between these combined rotations and the phenomena of motion in a cosmical planetary
or solar system. In both cases we have a central
body acting as source of energy and encircled by an- 